\title{
Stabilisation du fromage de Camembert par congélation
}

\author{
Irmina JARMUL, A. REPS, Krystyna WISNIEWSKA \\ et L. JEDRYCHOWSKI
}

\begin{abstract}
RESUME
Les essais réalisés ont montré qu'il est possible de conserver le fromage de Camembert à $-27^{\circ} \mathrm{C}$ pendant 2 ou 3 mois.

Le procédé le plus satisfaisant consiste à congeler le fromage immédiatement après le salage et ensuite, après décongélation, à lui faire subir un affinage de 2 semaines. La congélation du fromage âgé de 3 semaines peut aussi être recommandée, le fromage est alors bon à consommer immédiatement après la décongélation.

Mots clés : Fromage - Camembert - Congélation - Conservation.
\end{abstract}

\section{SUMMARY}

CAMEMBERT CHEESE STABILIZATION BY DEEP FREEZING

Camembert cheese from pasteurized milk $\left(72^{\circ} \mathrm{C} / 15 \mathrm{~s}\right)$ was made on industrial scale. After salting, and 1,2 and 3 weeks of ripening it was packed in aluminium foil, freezed in a cold room at $-27^{\circ} \mathrm{C}$ and $75 \% R H$ and stored under the conditions 2 and 3 months.

The possibility of Camembert storing at $-27^{\circ} \mathrm{C}$ was stated.

During the storage of Camembert cheese at this temperature fat changes proceeded faster than proteolysis. Ripening of salted and frozen cheese after thawing was quicker than the ripening of cheese which was not frozen.

The most favourable was the freezing of cheese directly after salting and then subjected for ripening during 2 weeks after thawing. Also of us was the storage at $-27^{\circ} \mathrm{C}$ of, 2 weeks ripened cheese as it was ready for consumption just after thawing.

Key words : Camembert cheese - Freezing - Storage.

Institut du Génie et de la Biotechnologie alimentaire, Université Agrotechnique d'Olsztyn (Pologne). 


\section{INTRODUCTION}

Les recherches de plusieurs auteurs (Filczakowa et al., 1978; Gabrielanc et al., 1980; Nikolajew et al., 1971) ont démontré que les températures de -3 à $-5^{\circ} \mathrm{C}$ étaient les plus favorables pour la conservation des fromages affinés. Il a été en effet constaté que les fromages ne pouvaient être conservés dans de bonnes conditions qu'aux températures supérieures à leur point de congélation. Placé au-dessous de $-10^{\circ} \mathrm{C}$ un fromage perd de sa qualité après décongélation; il devient cassant et sa croûte se fend. Quant au fromage de Camembert, il ne peut pas être conservé longtemps, même aux températures de -3 à $-5^{\circ} \mathrm{C}$.

Notre étude a porté sur la conservation du fromage de Camembert par congélation. En comparaison avec les fromages à pâte dure une modification de la consistance de la pâte a en effet moins d'importance dans l'appréciation organoleptique.

\section{PROTOCOLE EXPERIMENTAL}

Le fromage du genre Camembert était produit à partir de lait pasteurisé $\left(72^{\circ} \mathrm{C} / 15 \mathrm{~s}\right)$ industriellement.

Après le salage et après 1,2 ou 3 semaines d'affinage, le fromage était emballé, empaqueté en feuille d'aluminium et réfrigéré dans une chambre frigorifique et conservé à une température de $-27^{\circ} \mathrm{C}$ et une humidité relative de l'air de $75 \%$. Après décongélation, les fromages étaient affinés pendant 3,2 ou 1 semaines respectivement.

Pour observer l'influence de la congélation et de la conservation à $-27^{\circ} \mathrm{C}$ sur la qualité du fromage à divers degrés de maturation et sur l'évolution du processus d'affinage, il a été procédé à un examen organoleptique par un groupe d'experts et à un certain nombre de déterminations analytiques :

- teneurs en eau, en matière grasse;

- $\mathrm{pH}$;

- proportions de composés azotés solubles à pH 4,6 (Stadhouders, 1960), d'azote non protéique (Schober et al., 1961) et d'azote des acides aminés (Sode-Mogensen, 1948) ;

- acidité de la matière grasse.

\section{RESULTATS ET DISCUSSION}

On sait que pour obtenir des caractéristiques typiques d'un fromage, il est nécessaire d'assurer une acidification lactique et 
TABLEAU $1-T A B L E 1$

Evolution de la teneur en eau et du $\mathrm{pH}$ des fromages en cours d'affinage après conservation à $-27^{\circ} \mathrm{C}$

Evolution of water content and $\mathrm{pH}$ of cheeses during ripening after storage at $-27^{\circ} \mathrm{C}$

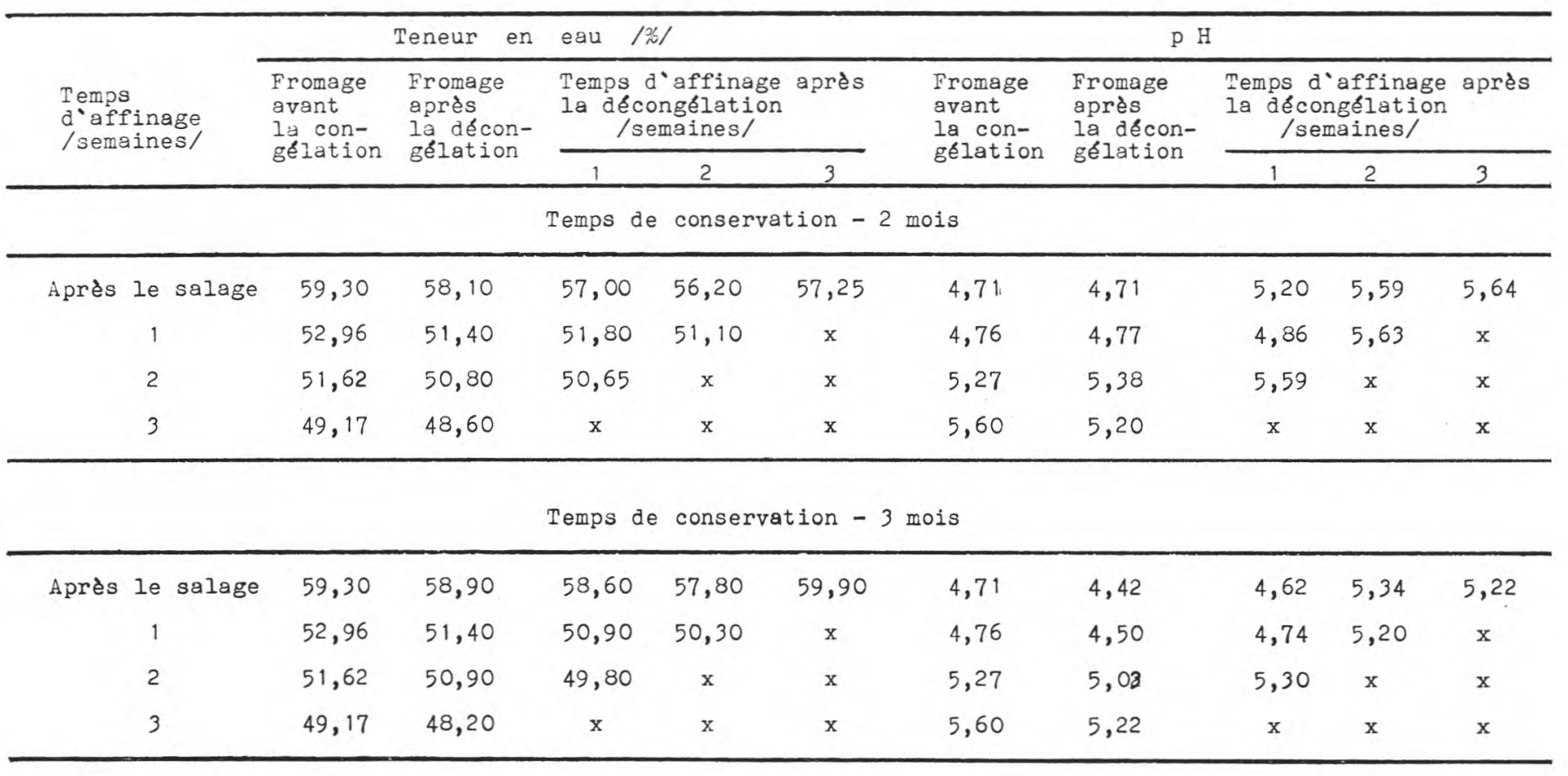


une déshydratation de la pâte convenables et propres au type de fromage considéré.

Il a été observé que, sans égard à la durée de conservation à $-27^{\circ} \mathrm{C}$ et au degré de maturation du fromage au moment de la congélation, les pertes d'eau au cours du stockage étaient insignifiantes (tab. 1). Il s'agit là d'un fait important car les pertes superficielles d'humidité ne sont pas compensées par une migration d'eau de l'intérieur du produit. Une déshydratation trop forte de la surface du fromage, jusqu'à $25-35 \%$ de teneur en eau, entraîne la formation d'une couche de structure poreuse, qui favorise les processus d'évaporation et l'absorption des odeurs étrangères.

On a constaté que, pendant toute la durée de l'affinage, la teneur en eau du fromage congelé aussitôt après salage, est beaucoup plus élevée que celle des fromages affinés avant congélation. Dans le premier cas, l'évaporation de l'eau au cours de la maturation est en effet relativement faible; ce pourrait être dû au développement de moisissures superficielles plus intense qui est alors observé. Pourtant, cette différence n'a pas d'influence significative sur la qualité du produit après une période de 2 semaines d'affinage bien que le fromage se caractérise par un arôme plus complet, en comparaison avec les échantillons affinés pendant le même temps avant congélation.

Le $\mathrm{pH}$ des caillés en fin d'égouttage est normal et voisin de 4,7 . Toutefois la désacidification au cours de la maturation des fromages non congelés est lente, les $\mathrm{pH}$ de pâte étant respectivement 4,76, 5,27 et 5,60 après 1,2 et 3 semaines d'affinage alors que le $\mathrm{pH}$ d'un Camembert affiné se situe dans les limites de 6,0-6,5 (Kikuchi, 1966).

Pendant la conservation à $-27^{\circ} \mathrm{C}$ le $\mathrm{pH}$ des fromages tend à diminuer (tab. 1) surtout après 3 mois de stockage. Cet abaissement du $\mathrm{pH}$ pourrait être dû à la destruction mécanique des germes microbiens par congélation.

La dégradation des protéines pendant la conservation du fromage à $-27^{\circ} \mathrm{C}$ apparaît peu marquée (tab. 2). On peut observer que la teneur en azote soluble à $\mathrm{pH}$ 4,6 diminue au cours du stockage, alors que celle en azote aminé augmente et que les proportions de composés azotés non-protéiques restent à un niveau à peu près constant. Il semble donc ne pas y avoir à $-27^{\circ} \mathrm{C}$ inhibition de l'activité de la présure et des endopeptidases microbiennes à l'origine de la formation de peptides à partir des caséines (Desmazeaud et Gripon, 1977 ; Poznanski et al., 1965) mais une certaine dégradation des peptides en acides aminés peut s'effectuer ou se poursuivre par l'action des exopeptidases microbiennes qui seraient ainsi moins sensibles à l'abaissement de température.

Il est également constaté que l'affinage du fromage congelé après le salage, s'effectue après décongélation plus rapidement que 
TABLEAU $2-T A B L E 2$

Dégradation des protéines des fromages au cours de l'affinage après conservation à $-27^{\circ} \mathrm{C}$

Proteolysis in cheeses during ripening after storage at $-27^{\circ} \mathrm{C}$

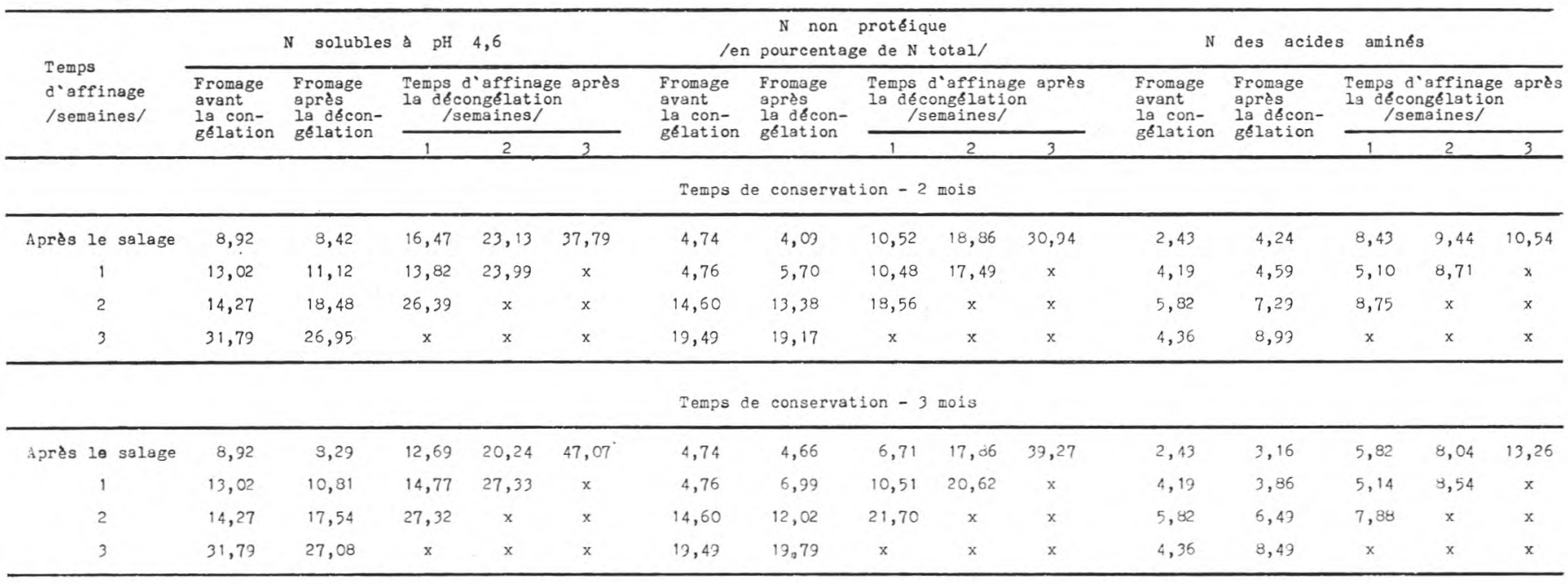


celui du fromage non congelé; il dépend de la durée du stockage à $-27^{\circ} \mathrm{C}$, le degré de protéolyse étant particulièrement élevé après 3 mois de conservation. Toutefois la vitesse de dégradation des protéines au cours de l'affinage est influencée par le degré de maturation du fromage à la congélation. Avec les fromages âgés de 1 et 2 semaines, la protéolyse après décongélation est moins rapide que celle du fromage congelé immédiatement après le salage.

Les modifications de la matière grasse ont été étudiées en se basant sur la détermination de l'acidité de cette phase; on sait en effet que la teneur en acides gras libres a une grande influence pour la formation du goût et de l'arôme des fromages (Bills et Day, 1964 ; Dixon et al., 1969; Jarmul et al., 1983; Kowalewska et al., 1976).

On a observé que pendant le stockage à $-27^{\circ} \mathrm{C}$ une lipolyse non négligeable se produit (tab. 3). Ainsi après 2 mois de conser-

\section{TABLEAU $3-T A B L E 3$}

Evolution de l'acidité de la matière grasse des fromages en cours d'affinage après conservation à $-27^{\circ} \mathrm{C}$

Evolution of fat acidity in cheeses during ripening after storage at $-27^{\circ} \mathrm{C}$

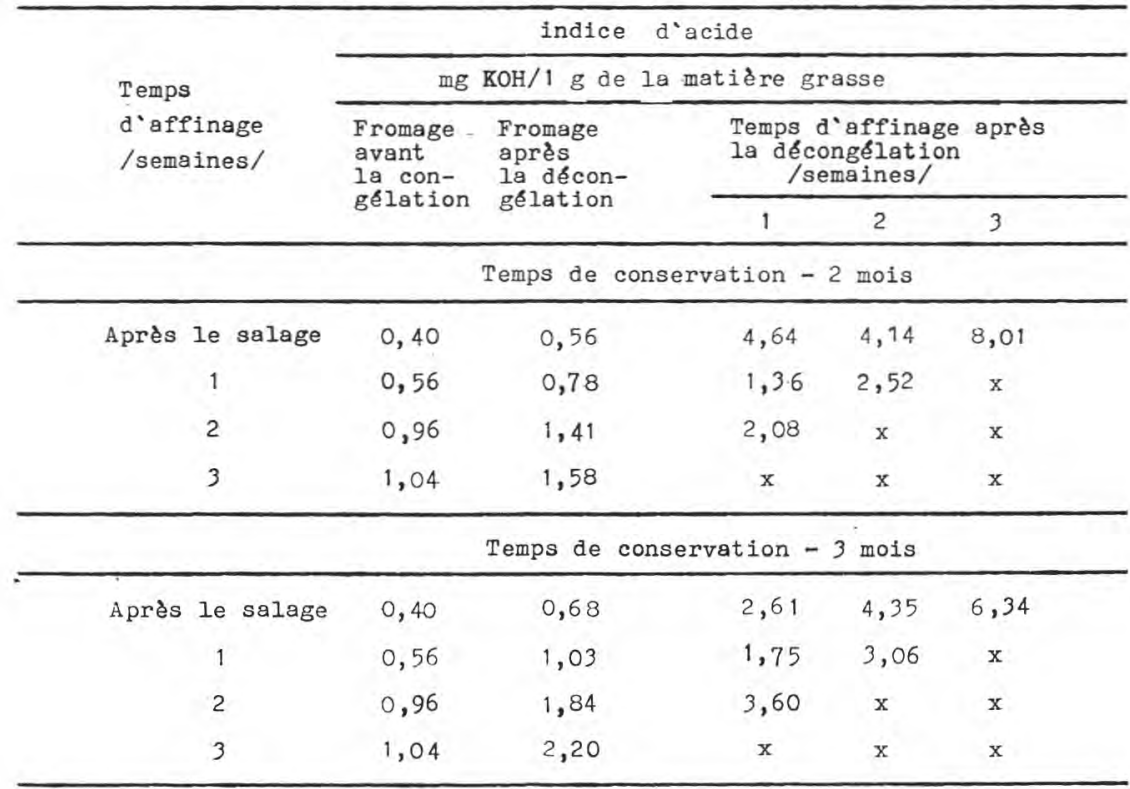

vation l'augmentation de la teneur en acides gras libres atteint 40 à $50 \%$ et elle est proche de $100 \%$ après 3 mois. Il apparaît donc que les lipases conservent une certaine activité aux très basses températures. 
Il est également remarqué que la libération des acides gras est plus grande et plus rapide dans les fromages soumis à l'affinage après le stockage à l'état congelé, cette libération étant plus intense dans le cas des fromages congelés aussitôt après salage.

Il se produit donc une accélération particulièrement marquée du processus d'affinage, de la protéolyse et de la lipolyse, dans les fromages congelés après salage, donc à l'état de caillés frais.

Cette accélération est probablement en grande partie liée à la teneur en eau qui est sensiblement plus élevée que dans les autres fromages et qui, par suite, influence favorablement le développement des micro-organismes, notamment des moisissures, tout en intensifiant les actions enzymatiques.

Toutefois la congélation et la conservation prolongée à basse température peuvent être à l'origine de certaines modifications dans la structure des substrats qui pourraient ainsi devenir, après décongélation, plus accessibles et/ou plus sensibles à l'action des enzymes. L'évolution des protéines (tab. 2) ne permet pas de retenir cette hypothèse car le degré de protéolyse des fromages congelés après 1 ou 2 semaines d'affinage n'est pas supérieur à celui des échantillons affinés sans congélation. Il n'en est pas de même en ce qui concerne la lipolyse qui est nettement plus forte dans les fromages ayant subi une congélation, sans doute en raison d'une désorganisation de la membrane des globules gras qui rendrait plus facile et plus rapide l'action des lipases sur les triglycérides.

Cependant le problème le plus important pour le fromager concerne les qualités de saveur et d'arôme, de texture et de consistance qui doivent être satisfaisantes et typiques du fromage considéré afin que le produit soit bien accepté par les consommateurs.

Les examens organoleptiques effectués par un groupe d'experts ont montré que la congélation et la conservation du Camembert à $-27^{\circ} \mathrm{C}$ n'entraînaient pas de détérioration des caractéristiques de qualité du fromage. La solution la plus favorable est de congeler le fromage immédiatement après le salage et, après la décongélation, de lui faire subir un affinage dont la durée ne doit pas dépasser 2 semaines. Les résultats obtenus montrent également qu'un fromage affiné de 2 semaines peut être congelé et conservé à $-27^{\circ} \mathrm{C}$ mais il devra être mis en vente immédiatement après décongélation.

\section{REFERENCES BIBLIOGRAPHIQUES}

BILls D.D., DAY E.A., 1964. Determination of the major free fatty acids of Cheddar cheese. J. Dairy Sci., 47, 733.

DesmazeAud M.J., Gripon J.C., 1977. General mechanism of protein breakdown during cheese ripening. Milchwissenschaft, 32, 731. 
Dixon R.P., Deman J.M., Wood F.W., 1969. Production of volatile acids during Cheddar cheese ripening. Can. Inst. Food Technol. J., 2, 3, 127.

Filczakowa N.N., Mojsiejewa R.M., Mierkulowa A.N., 1978. Przechowywanie serow podpuszczkowych w minusowej temperaturze. Cholodil'naja Technika, 12, 37.

Gabrielanc M.A., SzePlowa L.N., Karpowa S.J., 1980. Przechowywanie twardych podpuszczkowych serow $\mathrm{w}$ komorach chlodniczych $\mathrm{z}$ ozonowanien powietrza. Cholodilnaja Technika, 5, 35.

Jarmul I., Reps A., Poznanski S., Zelazowska H., 1983. Wolne lotne kwasy tluszczowe $w$ serze produkowanym przy uzyciu mieszaniny pepsyny $\mathrm{z}$ mikrobiologicznymi substytutami podpuszczki. Zesz.nauk.ART Olszt., 18, 79.

KIKUCHI T., 1966. Observations on Camembert cheese ripening. XVII Int. Dairy Congr., D:2, 313.

Kowalewska J., Poznanski S., Krefft R., 1976. Ksztaltowanie sie poziomu wolnych kwasow tluszczowych w zaleznosci od zmian technologii wyrobu era. Zesz. nauk. ART Olszt,. 8, 3.

NikolaJew A.J., Sacharow S.B., 1971. Zmiany jakosci serow kostromskiego, holenderskiego o ulepszonej konsystencji w czasie dlugiego przechowywania w chlodniach. Molocznaja Promyszlennost., 4, 13.

PozNANSKi S., Lenoir J., Mocouot G., 1965. La protéolyse de la caséine par les enzymes intracellulaires de certaines bactéries. Lait, 45, 3.

SCHOBER R., Niclaus W., Christ W., 1961. Anwendung der " Finger-AbdruckMethode " auf die Kennzeichnung vor Käsesorten durch ihre proteolytischen Inhaltsstoffe. Milchwissenschaft, 16, 140.

Sode-Mogensen T., 1948. Determination of the degree proteolytic decomposition in cheese with special reference to the formal titration. Meddelande, No 21, Fran Statens Mejeriförsök, Alnarp-Akarp.

StADHOUDERS I., 1960. The hydrolysis of protein during the ripening of dutch cheese. The enzyme and bacieria involved. Neth. Milk Dairy J., 14, 83. 